\title{
Prospección arqueológica de una laguna de altura (Busa), cantón San Fernando"
}

Alden Yépez ${ }^{1}$

\begin{abstract}
RESUMEN
LOS PROCESOS DE OCUPACIÓN HUMANA PREHISPÁNICA EN LA CABECERA DEL RÍO JUBONES, EN EL AUSTRO ECUATORIANO, PROBABLEMENTE ESTUVIERON SUJETOS A LAS FUERTES VARIACIONES CLIMÁTICAS PROVOCADAS POR EL FENÓMENO DE

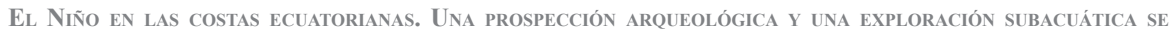
realizaron en la laguna de Busa, cantón San Fernando, Azuay durante el verano del 2009. La laguna

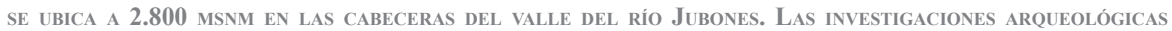
REVELARON DOS PERÍODOS DE OCUPACIONES: UNO PREHISPÁNICO, POSIBLEMENTE CON UN COMPONENTE FORMATIVO, Y UNO COLONIAL PROBABLEMENTE TEMPRANO. LA EVIDENCIA DE MATERIAL CULTURAL PREHISPÁNICO AL INTERIOR

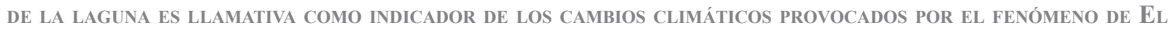
NiÑo, LOS MISMOS QUE DETERMINARAN EL CRESCIMIENTO Y DECRECIMIENTO DEL NIVEL DE AGUA DE LA LAGUNA. LA TRADICIÓN ORAL DE LOS MORADORES DE BUSA REFLEJA EN PARTE ESTOS LOS CAMBIOS CLIMÁTICOS. LOS HALLAZGOS DE TUMBAS EN ABRIGOS ROCOSOS ALREDEDOR DE LA LAGUNA INDICAN QUE ESTE LUGAR TUVO CONNOTACIONES SAGRADAS PARA LOS ABORÍGENES.
\end{abstract}

Palabras claves: busa- formativo- COlonial- El Niño- tumbas en abrigos rocosos

Abstract

The processes of human occupation in the head of the Jubones River, in the Ecuadorian Region of Austro, WERE PROBABLY SUBJECTED TO HEAVY CLIMATIC VARIATIONS PROVOKED BY THE EL NiNO PHENOMENON ALONG THE ECUADORIAN COAST. AN ARCHEOLOGICAL SURVEY AND UNDERWATER EXPLORATION WERE CARRIED OUT IN THE BUSA Lagoon, San Fernando County, Azuay, during the summer of 2009. The Lagoon is located at 2.800 Meters in THE RIVER VALLEY OF THE JubONES RiVER. ARCHEOLOgICAL INVESTIGATION REVEALED TWO PERIODS OF OCCUPATION: ONE PRE-Hispanic, POSSIBly a FORMative COMPONENT, AND ONE COLONIAL (MOST LIKElY EARLy COLONIAL). The PRE-HISPANIC MATERIAL EVIDENCE IN THE INTERIOR OF THE LAGOON IS EYE-CATCHING AS AN INDICATOR OF THE CLIMATE CHANGES PROVOKED BY THE El NINO PHENOMENON, THOSE SAME CHANGES WHICH DETERMINED THE RISING AND FALLING OF THE LEVELS OF WATER IN THE LAGOON. THE ORAL TRADITION OF THE INHABITANTS OF BUSA PARTIALLY REFLECTS THESE CLIMATE CHANGES. THE DISCOVERY OF ROCK-COVERED TOMBS AROUND THE LAGOON INDICATES THAT THIS PLACE HAD SACRED CONNOTATIONS FOR THE ABORIGINALS.

KEYWORDS: BUSA- FORMATIVE - COLONIAL - EL NIÑO - TOMBS IN ROCK SHELTERS

1 Institut VII, Abteilung für Altamerikanistik. Universität Bonn. Tel.: (+49)(0)228/73-4413. e-Mail: rbi_am@yahoo. com 


\section{Introducción}

$\mathrm{E}$ stos son los resultados más importantes del procesamiento de datos arqueológicos y etnográficos de la investigación desarrollada en el proyecto "Prospección arqueológica en una laguna de altura (Busa), cantón de San Fernando", un proyecto impulsado y financiado por el INPC- Regional 6 con sede en la ciudad de Cuenca y desarrollado durante el verano del año pasado. En este reporte se intenta una aproximación histórico cultural del proceso de ocupación en los alrededores de la laguna de Busa y en parte en su interior.

Este proyecto fue planteado inicialmente como uno de "Prospección subacuática en la Laguna de Busa". Sin embargo dada la carencia de la infraestructura para realizar una investigación subacuática, fue necesario replantear la metodología de prospección. Con el objetivo de identificar sectores específicos de la laguna que revelen algún potencial arqueológico, se realizó una prospección terrestre alrededor de la laguna. Con base en los resultados preliminares de la prospección terrestre se hizo una extensión explorativa subacuática en la laguna.

Este proyecto también cuenta con elementos etnográficos que nos permitieron conocer en algo sobre la memoria oral colectiva de la ciudad de San Fernando de Busa y sus alrededores.

La socialización de la información acompañó a la recolección de la información etnográfica y arqueológica desde el inicio de este proyecto. Superando algunas dificultades fue posible obtener el respaldo total de los moradores de San Fernando de Busa.

\section{Ubicación geográfica y contexto etnohistórico de la laguna de Busa}

La laguna de Busa hace parte del sistema orográfico de los Andes Meridionales del Ecuador, los mismos que inician al sur del nudo del Azuay y se caracteriza por la presencia de mesetas volcánicas altas (3.600 a $4.700 \mathrm{msnm}$ ) y de ondulaciones moderadas del terreno. Las hoyas en esta zona son mucho más profundas que aquellas de los Andes Septentrionales ecuatorianos, mayormente conocidos como parte de la subregión septentrional andina. Al sur del nudo del Azual hay dos depresiones andinas que se orientan de noreste a suereste: 1.- Cuenca- Santa Isabel y 2.- Gualaceo- Nobón- Saraguro.

La laguna de Busa se ubica justamente en una de las mesetas altas que colindan en su costado este con la depresión andina Cuenca- Santa Isabel (ver Figura 1). Esta depresión se conecta más abajo con la cuenca del río Jubones, el mismo que está a unos $20 \mathrm{~km}$ de distancia en línea de la laguna de Busa. Esta laguna hace parte de la cuenca hídrica del río Jubones. De hecho las aguas que salen de la laguna se descargan en un río local conocido como Rircay y más tarde se unen con las aguas del río Zhururcay para formar el río Jubones.

La laguna de Busa se ubica a 2.800 msnm y está al pié del cerro conocido localmente con el nombre de San Pablo. Este cerro es evidentemente de origen volcánico y promedia una altura de $3620 \mathrm{msnm}$. Las rocas grandes y dispersas en los alrededores no evidencian, sin embargo, una erupción violenta, sino más bien una lenta y no acabada. Es muy probable que el arrastre de lava durante la formación del cerro San Pablo provocó una ondulación suficientemente profunda en el terreno, para dar paso a la formación de la laguna de Busa, la misma que recibe las aguas del páramo y seguramente de las filtraciones subterráneas del cerro San Pablo.

Según las fuentes etnohistóricas tempranas que existen, se puede identificar algunos accidentes geográficos que son los mismos accidentes descritos aquí. Así por ejemplo la hoya del río Jubones corresponde con la denominación "Cañaribamba", utilizada por el soldado español Cieza de León, para describir una de las tres secciones ocupadas por el país Cañari. Las otras dos secciones fueron "Hatun- Cañar" y "Tomebamba", denominaciones que correspondían a las hoyas de los ríos Cañar y Paute, respectivamente (Moreno-Yánez, 1983: 96-97). Es posible asumir que esta división tiene sus orígenes en épocas anteriores a la invasión incaica. Solo en las 
inmediaciones del cantón Santa Isabel, al norte del río Jubones, fueron detectados, mediante una prospección no sistemática regional, al menos tres sitios arqueológicos (Husaipampa, Parroquia Cañaribamba y Cerro Shaishapa) con componentes aparentemente incaicos y preincaicos (Odaira, 1997: 72-77). En la cuenca alta del río Jubones, en la confluencia de los ríos Rircay y León, se detectaron igualmente un número significativo de sitios arqueológicos que muy probablemente corresponden con el asentamiento "Cañaribamba", mencionado anteriormente (Ibid: 72-73 y Fig. 1).

Según las indicaciones etnohistóricas tempranas y la dispersión de los sitios arqueológicos al norte del río Jubones, se puede inferir con un cierto grado de confiabilidad que las inmediaciones de la laguna de Busa fueron parte del paisaje que conocieron los Cañaris del Cañaribamba.

\section{Estrategias de prospección sistemáticas}

\section{Prospección sistemática terrestre}

La búsqueda de vestigios de ocupación humana en la laguna de Busa se basó en el supuesto de que los restos cerámicos que quedan en el terreno, pueden ser considerados evidencias de basura prehispánica o colonial. Dependiendo de la distribución de la basura, es posible hacer inferencias respecto de las áreas de ocupación y de la densidad de las áreas ocupadas. Para ello se diseñó una estrategia de prospección que cubrió toda la superficie del terreno. La prospección fue de carácter sistemático, siguiendo líneas imaginarias, separadas cada una a una distancia de $20 \mathrm{mt}$., fue posible trazar un reticulado geo-referenciado cuyas intersecciones distaron a $20 \mathrm{mt}$. En esas intersecciones se colocaron las pruebas de pala para buscar tiestos como evidencia de ocupación humana antigua. Debido a que el suelo está cubierto por pasto para el ganado, no fue posible realizar recolecciones de superficie. Solo se realizaron pruebas de pala (333) para una superficie de 23,23 ha distribuida en los alrededores de la laguna de Busa (ver figura 2).

\section{Exploración sistemática subacuática}

Adiferencia de la prospección terrestre, la prospección subacuática tuvo un carácter explorativo, más que recolectivo. Esto se explica por el replanteo de los objetivos de la investigación (como se mencionó en el capítulo introductorio de este informe), a los medios locales disponibles y al carácter mismo de la exploración subacuática.

Una investigación subacuática en la laguna de Busa hubiese requerido de una infraestructura para dragar los depósitos de sedimentos acumulados, la cual no estuvo contemplada en la realización de este proyecto. Se contó por el contrario con la presencia de dos buzos experimentados y suficiente aire en los tanques para explorar la laguna durante 10 horas de buceo. El área de superficie de la laguna que fue explorada mediante inmersiones subacuáticas es de 11,77 ha.

\section{Resultados}

De las 333 pruebas de pala practicadas durante la prospección terrestre, 175 resultaron ser positivas, es decir contuvieron restos de material cultural (fragmentos de cerámica y lítica). Los fragmentos de cerámica o tiestos fueron 1027 y los fragmentos líticos 63. Debido al volumen del material se prefirió procesar (lavar, secar y codificar) el material cerámico para los análisis respectivos. Las pruebas negativas, es decir sin restos de material cultural, fueron 158.

Las pruebas de pala positivas se concentran principalmente en el sector sureste de la laguna de Busa y suman un total de 110 (ver figura 3). En este sector las pruebas arrojaron un total de 861 fragmentos cerámicos principalmente. En el sector noreste, la presencia de pruebas positivas 
es escasa y dispersa. El número de fragmentos cerámicos aquí fue de 166, de un total de 65 pruebas. Esta distribución irregular de materiales en el terreno, entrega pistas importantes para comprender la ocupación del paisaje en los alrededores de la laguna de Busa.

Las pruebas de pala negativas se concentran principalmente en el sector noroeste de los alrededores de la laguna de Busa. En la figura cuatro se observa una distribución regular en el sector noroeste de las pruebas de pala negativa, en tanto que en el sector sureste, éstas se encuentran distribuidas de manera dispersa y aislada en el terreno. Quizás tan importante como explicar la presencia de pruebas de pala positivas en el sector sureste, es explicar la ausencia de ellas en el mismo sector.

Un factor importante que explica la dispersión de los materiales culturales en la región prospectada, tiene que ver con la relación positiva que existe entre la gradiente del terreno y los tiestos. Esta relación presupone que un terreno plano tiene mayores posibilidades de ser ocupado que un terreno inclinado, a no ser que haya componentes tecnológicos o culturales que justifiquen la ocupación de un terreno inclinado. Por consiguiente mientras más inclinado sea el terreno, menores vestigios de ocupación se esperan encontrar en él y mientras más plano sea el terreno, mayores vestigios se deben encontrar en él. Las cotas de altura del terreno prospectado variaron muy poco: de $2830 \mathrm{msnm}$ al filo de la laguna, hasta 2885 al costado noroeste de la laguna (ver figura 2). Los resultados de las exploraciones subacuáticas se expondrán con detalle en el acápite IV.

\section{Clasificación de la cerámica}

\section{Definición}

La clasificación aquí empleada es macroscópica. Para ello se usó una lupa con un aumento de 8 veces para la clasificación de los 1027 tiestos.

Los tiestos identificados como diagnósticos fueron 109, entre ellos, 54 bordes, 3 bases, 4 cuellos, 3 polípodos y 45 cuerpos decorados. Dada la escasa cantidad de fragmentos diagnósticos y dado el hecho de que ninguno de los bordes, bases o cuellos permitió hacer una clasificación de formas cerámicas, se decidió trabajar principalmente con el mayor corpus cerámico, es decir con los 918 fragmentos de cuerpos cerámicos.

El concepto mediante el cual se clasificó y analizó el corpus de 918 fragmentos fue el de alfar. En inglés se conoce como "fabric" y, en alemán como "Ware" (Owen, 1996: 79). A diferencia del concepto tradicional de pasta, para clasificar un alfar se da el mismo valor clasificatorio a la superficie interior y exterior, así como la estructura interna de un fragmento cerámico (Bauer et.al., 1986). Es decir que para que un tiesto se clasifique como alfar, primero se examina neutralmente la estructura de la pasta y las superificies del tiesto. Según la clasificación tradicional, para clasificar un tiesto se tomaba en cuenta principalmente las superficies de la pasta, y de éstas superficies se daba mayor énfasis a la superficie externa.

Los alfares diagnósticos son aquellos que fueron seleccionados como relevantes para este estudio. No se tomaron en cuenta aquellos alfares que no aparecieron en el sondeo practicado y que por lo tanto no parecen ser importantes para el establecimiento tentativo de una cronología relativa.

De un total de 15 alfares identificados, se seleccionaron solamente 8 alfares. Cada alfar tiene un nombre, signado según los números ordinales del sistema decimal.

\section{Posición relativa de los alfares en el pozo de sondeo}

El criterio directriz para la representación gráfica de los alfares en las capas de suelo, según los niveles de excavación, fue la densidad de los tiestos por volúmen de suelo excavado. Así en 
la capa I, nivel 3, el alfar 1 aparece 6 veces, y el volúmen excavado es de $0,2 \mathrm{~m}^{3}$, su densidad medida en $\mathrm{m}^{3}$ será de 30 .

La representación gráfica de los alfares en las capas excavadas indica por lo tanto la densidad de alfares en las capas de suelo cavado y no la cantidad de tiestos de cada alfar en las capas de suelo (ver figura 5).

La figura 5 está compuesta por la representación simplificada de la estratigrafía de la pared oeste del pozo de sondeo y por la representación de los alfares según las capas de suelo excavado con cada uno de los rectángulos siguiendo los niveles arbitrarios de la excavación. La estratigrafía de esta pared reproduce la misma estratigrafía que la pared norte. Las capas I, II, III y IV, se mantienen bastante regular y casi horizontales tanto en la estratigrafía de la pared oeste como en la pared norte.

La distribución de la representación de los alfares en la estratigrafía de la pared oeste (y por ende de la pared norte) ordena claramente dos ocupaciones. Una primera ocupación, representada por el conjunto de los alfares 15,5 y 8 , está concentrada principalmente por debajo de la capa Ia, en las capas II y III. Este conjunto de alfares se caracteriza por la evidencia de una tecnología prehispánica, manifiesta en el uso de engobe presente en las paredes de los tiestos. De estos alfares, el 15, debido a sus paredes tan delgadas (3-4 mm.) puede ser asociado con cierto grado de confiabilidad con el tipo cerámico "cáscara de huevo", característico de las fases tempranas de Pirincay datadas entre 900 a 300 a.C. Según la descripción que se hace de la cerámica encontrada en Cerro Narrío, el alfar 15 encontrado en Busa, podría ser identificado como el tipo "Narrío rojo sobre leonado":

"El color es generalmente leonado y claro y la fluctuación no es grande. Es una alfarería bien trabajada y acabada. En esta cerámica básica el exterior del tiesto está raramente ennegrecido. Su espesor varía de $\mathbf{3 , 5}$ a $\mathbf{8 , 5} \mathbf{~ m m}$. La dureza varía de 3 a 4,5 (en la escala de Moh) (resaltado mío)" (Collier y Murra, 1982: 62)

Lastimosamente y dado que este tipo “... se lo encuentra a través de todos los períodos de Cerro Narrío" (Ibid), no es posible precisar la referencia cronológica cruzada del alfar 15 con el tipo "cáscara de huevo" de Pirincay.

Una segunda ocupación la representan el conjunto de alfares 10,11 y 14. Estos alfares si bien aparecen a finales de la capa II, aumentan considerablemente en las capas Ia y I, decrecen sustantivamente por encima de la capa I, es decir en la capa de humus. De estos tres alfares, los alfares 10 y 11 tienen superficies vidriadas, lo que se debe considerar como una prueba clara de una ocupación colonial (Buys: 1990: 61-72) en la laguna de Busa, aunque es difícil asignarla a una fase colonial temprana (siglo XVI) o a una más tardía (siglo XVII-XVIII).

Un tercer conjunto de alfares, los alfares 1,2 y 7 , aparecen en todas las capas excavadas y por esta razón es difícil considerarlos como alfares con significación cronológica. Más aún el grado de fragmentación alto de los tiestos dificulta su comparación con otros complejos cerámicos y a esto se agrega el problema de las terminologías locales para describir complejos cerámicos regionales. Pese a estos inconvenientes, el considerable volúmen en las capas Ia, I y en la capa humífera, de estos tres alfares, nos hacen pensar en la posibilidad de una tercera ocupación, ahí donde la cantidad de tiestos de los alfares 10,11 y 14 declina y 1,2 y 7 se mantiene constante.

\section{Exploraciones subacuáticas}

Las exploraciones subacuáticas fueron sistemáticas. Las exploraciones se realizaron siguiendo líneas imaginarias orientadas de norte a sur y distantes unas de otras a unos $40 \mathrm{mt}$. Los datos recuperados permitieron conocer acerca de la batimetría de la laguna. 


\section{Hallazgos}

En la esquina suroeste de la laguna se encontraron a la profundidad de $2 \mathrm{mt}$. unos fragmentos cerámicos grandes que juntos formaron una vasija semicompleta (ver figuras 6 y 7). Las características del alfar de esta vasija corresponden en gran medida al alfar 1 de la clasificación general de los tiestos recuperados de la prospección terrestre.

Para descartar la posibilidad de que esta vasija fue arrojada a la laguna como una especie de ofrenda, fue necesario conocer más sobre el proceso de formación de la laguna. Los resultados de la sedimentación formada en la laguna hacen interpretar la presencia de esta vasija como el producto de una ruptura in situ, como efecto de los vestigios dejados por una de las ocupaciones que estuvieron dominando un gran sector de la laguna, cuando el nivel de agua de ésta había bajado drásticamente.

Aparte de estas evidencias, se pudo recuperó de las orillas del sector 2, en su costado norte, material moderno, el mismo que no fue registrado.

\section{Proceso de formación de la laguna de Busa}

Dada la dificultad de tomar pruebas de los sedimentos provenientes del interior de la laguna, se practicó un cateo profundo al costado suroeste de la laguna (ver figura 2). Puesto que aquí el declive del terreno era bastante pronunciado se esperaba que las capas de sedimento encontradas sea significativas para hacer inferencias respecto del proceso de formación de la laguna.

\section{Estratigrafía del corte}

El corte realizado a orillas de la laguna alcanzó la profundidad de 1,30 mt. bajo la superficie y se lo realizó con la ayuda de una pala. Este corte no reveló material cultural alguno. En la capa más profunda se descubrió la "roca madre", la cual marcó el fin de la excavación.

Las capas de suelo más visibles fueron un total de 6, por debajo de la capa de humus y chamba. Cabe resaltar en este punto, que la visibilidad de las capas tiene que ver tiene que ver con los procesos de sedimentación de la laguna, los cuales, como se verá más adelante, estuvieron sujetos a dos constantes: períodos de intensas precipitaciones pluviales y períodos de prolongado estiaje con lluvias moderadas.

Las capas de suelo encontradas se distinguen unas de otras por sus colores y en parte por su composición macroscópica. Los colores de las capas alternan el negro oscuro o muy oscuro con el gris claro u oscuro. Fue muy interesante encontrar una relación positiva entre el color gris y la composición arcillosa del suelo y entre el color negro y la composición limosa del suelo. Las capas de color gris y textura arcillosa deben estar asociadas con los períodos de intensas precipitaciones pluviales, en tanto que las capas de color negro con textura limosa, deben estar asociadas con períodos de estiaje y lluvia moderada (ver cap. V.2. Inferencias).

Mirando la estratigrafía del corte a orillas de la laguna encontramos que la capa sobre la roca madre, es decir la capa VI, es un suelo limo arenoso de un color negro muy oscuro. La capa V es de arcilla limosa de un color gris claro. La capa IV tiene una textura limo arenosa de un color café negrizo muy oscuro. La capa III es un limo arcilloso de un color gris muy claro. La siguiente capa, la capa II, es una arcilla limosa de color gris oscura. La capa I es una capa de arcilla arenosa con un color de suelo café impuro, es decir con manchas ocres, amarillas y grises. Finalmente la capa de humus es de una textura limo arenosa y tiene un color negro oscuro. Las profundidades de cada una de las capas están descritas en la tabla 1. 


\begin{tabular}{|c|c|c|c|c|}
\hline Capa & Color & Textura & Profundidad b.s. & Observaciones \\
\hline Humus & negro oscuro & limo arenosa & $0-10$ & \\
\hline I & café impuro & arcilla arenosa & $10-35$ & $\begin{array}{l}\text { manchas ocre, ama- } \\
\text { rillo y gris }\end{array}$ \\
\hline II & gris oscuro & arcilla limosa & $35-55$ & \\
\hline III & gris muy claro & limo arcilloso & $55-78$ & \\
\hline IV & café negrizo muy oscuro & limo arenoso & $78-91$ & \\
\hline $\mathrm{V}$ & gris claro & arcilla limosa & $91-103$ & \\
\hline VI & negro muy oscuro & limo arenoso & $103-132$ & \\
\hline roca madre & & & & \\
\hline
\end{tabular}

Elaborado por el autor

El tipo de corte practicado a orillas de la laguna no nos permite hacer una aproximación más fina de los procesos geomorfológicos y climáticos que afectaron el proceso de formación de la laguna. Este corte por el contrario nos revela en algo los macroprocesos que explicarían la sucesión de las capas gris y oscura y sobretodo nos hace pensar en la necesidad de implementar nuevas investigaciones en los alrededores de la laguna y al interior de la laguna.

\section{Inferencias}

Los depósitos de sedimentos de este cateo revelan tres períodos de prolongado estiaje con lluvias moderadas en la región, lo que probablemente influyó en la reducción del nivel de agua de la laguna. Los depósitos de sedimentos revelan también períodos de intensas precipitaciones pluviales en la región, lo que quizás pudo haberse manifestado en la laguna como tres momentos de expansión. Las capas de suelo VI, IV y II, cuyas características son la composición limosa del suelo y su color predominante el negro, con sus variedades oscuras y muy oscuras, corresponderían a los períodos de estiaje y posiblemente a los momentos de reducción de la laguna. Esta interpretación encuentran apoyo en un estudio realizado en la laguna de Pallcacocha, aproximadamente $40 \mathrm{~km}$. en línea recta al norte de la laguna de Busa.

En Pallcacocha se identificaron láminas clásticas inorgánicas de colores claros (esencialmente grises) intercaladas con láminas ricas en sedimentos orgánicos, tal como se anotó arriba, y su formación se explica por efecto de fuertes precipitaciones pluviales que arrastran los sedimentos inorgánicos por drenaje interno:

"The inorganic laminae likely represent deposition from density- driven undercurrents that carried terrestrially derived clastic sediment and some organic matter into the 15-m-deep basin in response to brief storm events that mobilized the abundant loose sediment in the headwaters of the drainage basin as debris flows" (Donald: 2008: 518)

Según estos dos tipos de suelo (gris- arcilloso y negro- limoso) tanto la laguna de Pallcacocha como la laguna de Busa guardan paralelos que explican sus procesos de formación. No obstante a diferencia de la reconstrucción cronológica que se hace de los períodos de intensas lluvias alternados con los períodos de estiaje moderado en Pallcacocha, en la laguna de Busa no fue posible establecer una reconstrucción cronológica de estos procesos, toda vez que la muestra no fue sujeta a un análisis microscópico. Al parecer la superficie de la laguna de Busa fue ocupada hacia el interior al menos algunas decenas de metros respecto de su orilla actual por miembros de 
una población humana. Probablemente la laguna fue ocupada al menos en una ocasión, durante la época prehispánica, y quizás en una época del período formativo, según la presencia de tiestos datados en este período. Rozando los límites de la especulación es posible pensar también que poco antes o poco después de la llegada de los conquistadores españoles a esta región, la laguna se expandió una vez más, inundando una buena parte del sector norte y este de la laguna. De ahí que los alfares identificados como coloniales son prácticamente inexistentes en esta zona. Como refuerzo para esta hipótesis se debe echar una mirada a la memoria colectiva de San Fernando .

\section{La laguna de Busa en la memoria colectiva de San Fernando}

De las 17 entrevistas realizadas a los moradoes de San Fernando de Busa, la cabecera cantonal de San Fernando, existe un tema recurrente en casi todas las leyendas recuperadas de las entrevistas. Se dice que antiguamente la laguna creció de nivel porque un mendigo que pidió abrigo y comida en la casa de hacienda, que quedaba en lo que hoy es el centro de la laguna, fue expulsado de allí por los dueños de la hacienda. El mendigo, que en realidad era Jesús, subió a uno de los cerros y desde allí alimentó con un pozuelo de agua a una de las quebradas hasta que el nivelw del agua de la laguna subió e inundó la casa de hacienda y sus dueños perecieron en ella. De esta manera se explica en la mitología local, cómo se formó la laguna de Busa (ver figura 8).

Esta leyenda tiene elementos míticos fundacionales muy recurrentes en el callejón interandino y mezcla elementos aborígenes (la laguna como un ser con poderes destructores) e hispánicos (los hacendados y el Dios blanco disfrazado de mendigo) quizás está refiriéndose a un fenómeno climático relevante en el siglo XVI y que quedó en la memoria colectiva. Esta aseveración, sin embargo, debe ser contrastada con información paleoclimática.

Llama la atención de este relato el rol pasivo del cerro, como un mero transportador del agua derramada por el mendigo. Teniendo en cuenta que la superficie ocupada por la laguna durante sus fases de reducción debió ser muy pequeña, es difícil pensar en un rol sagrado de esta para las poblaciones que ocuparon sus orillas. La recurrencia de los relatos míticos en torno a la laguna de Busa, dirige nuestra atención al paisaje del sector que incluye al cerro San Pablo.

\section{Indicios sobre el rol sagrado del cerro San Pablo durante la época prehispánica}

El cerro San Pablo es un elemento del paisaje recurrente en la laguna de Busa. Este puede ser divisado desde varios puntos cardinales y su contraste con la laguna es verdaderamente espectacular (ver figura 9).

Una de las exploraciones arqueológicas reveló que detrás de la franja de árboles de pinos (ver figura 2) varios abrigos rocosos (al menos cuatro) habían sido utilizados. Restos de vestigios cerámicos principalmente de los alfares 1 y 2 estaban mezclados con huesos que parecían ser de mamíferos pequeños (cuyes?). Estos abrigos rocosos habían sido previamente saqueados y según los moradores, en estos abrigos se encontraron huesos humanos, sino esqueletos enteros. Un recorrido más detenido reveló la presencia de otros abrigos rocosos que posiblemente contienen enterramientos, dado que los lugares de entrada estaban bien sellados por una capa de piedra amontonada.

Por la estreches del tiempo no fue posible identificar los abrigos rocosos que aún contienen enterramientos, pero sí es posible decir que hay unas cuantas decenas de abrigos que pudieron haber servido como cuevas para depositar los cuerpos de los aborígenes. Este hecho le da el carácter de necrópolis a la zona de abrigos rocosos, lo cual nos permite hablar con certeza del rol sagrado que jugó el cerro San Pablo en la cosmovisión de las poblaciones aborígenes que vivieron alrededor y fuera de la laguna Busa. 


\section{Agradecimientos}

La prospección arqueológica y la exploración subacuática en la Laguna de Busa, fue posible gracias a la decidida colaboración del Dr. Joaquín Mosocos, Director del INPC- Regional 6, así como de sus colaboradores, el Dr. Napoleón Almeida y el Lcdo. Danilo Delgado. Igualmente debo manifestar mis agradecimientos al actual alcalde de San Fernando, Ing. Marco Peña, a los miembros del Comité de Veeduría para la conformación futura de un museo local, y por supuesto a todos los trabajadores de campo, quienes solidariamente colaboraron con este proyecto.

Unos agradecimientos especiales a mis asistentes de campo, Srta. Gabriela López, egresada del Dpto. de Antropología de la PUCE- Q y a la Lcda. Gabriela Cedillo, por su apoyo e incondicional colaboración. En este contexto debo indicar y agradecer que el diseño y elaboración del mapa topográfico estuvo a cargo del al Ing. Víctor Pinos. Finalmente, un reconocimiento muy especial a la labor desplegada por los busos profesionales Carlos Pacheco y William Seliger. A todos muchas gracias.

\section{Bibliografía}

Bauer Ingolf et.al. 1993, Leitfaden zur Keramikbeschreibung (Mittelalter-Neuzeit). Kataloge der prähistorischen Staatssammlung München, Beiheft 2. Kallmunz/ Opf.: Michael Lassleben.

Bowens, Amanda. 2009, Underwater archaeology: the NAS-guide to principles and practice, United Kingdom: Nautical archaeological society.

Bruhns, Karen. 2007, “Cerro Narrío, Pirincay y el Formativo Ecuatoriano”, en: Donald Collier y John Murra , Begnino Malo ., trad., Reconocimiento y Excavaciones en el Sur del Ecuador Apéndice D, Casa de la Cultura Ecuatoriana, Núcleo del Azuay, Cuenca, pp. 351-402.

Buys, Josef. 1990, “El convento de Santo Domingo de Quito”, en: Jaime Hidrovo y Alexandra Kennedy (eds.). Cerámica colonial y vida cotidiana, Fundación Paul Rivet, Cuenca, pp. 61-72.

Collier, Donald y John Murra. 1982, Reconocimiento y excavaciones arqueológicas en el sur del Ecuador, Cuenca, Centro de Estudios Históricos y Geográficos de Cuenca.

Kintigh, Keith W. 1988, “The effectiveness of subsurface testing: a simulation approach”, en: American Antiquity 53, pp. 686-707.

Kinne, Andreas. 2004, "Tabellen und Tafeln zur Grbungstechnik", ein: Hilfsmittel für die archäologische Geländearbeit. The Netherlands: IO-Graph V.O.F

Krakker, James J., Michael J. Shott, and Paul D. Welch. 1983, "Design and evaluation of shovel-test sampling in a regional archaeological survey", en: Journal of Field Archaeology 10, pp. 469-480.

Moreno Yánez, Segundo. 1983, “Formaciones político tribales y señoríos étnicos”, en: Ayala, E. (ed.), Nueva historia del Ecuador, vol. 2, Corporación Editora Grijalbo, Quito, pp. 15-134.

Meyers, Albert. 1998, "La tradición Tacalshapa y la arqueología del Cañar y Azuay en la sierra sur del Ecuador. Una secuencia a base de comparaciones con el norte del Perú", en: Sabine Dedenbach- Salazar Sáenz, Cármen Arellano Hoffmann, Eva König y Heiko Prümers (eds.). Bonner Amerikanistische Studien (BAS), 30, Anton Saurwein, Bonn, pp. 169-199.

Nance, Jack D. y Bruce F. Ball. 1986, "No surprises? The reliability and validity of test pit sampling”, en: American Antiquity 51, pp. 457-483.

Oberem, Udo. 1976, "El acceso a recursos naturales de diferentes ecologías en la Sierra Ecuatoriana (Siglo XVI)". en: Actes du XLII Congrès International des Americanistes, París 2-9- Septembre. Vol IV. París (Societé des Américanistes), pp. 51- 64.

Odaira, Shuichi. 1997, "Mirador de Moyepungo. Un sitio incaico en el sur de la provincia del Azuay", en: Netherly, P. (ed.), Fronteras de Investigación, 1(1), Fundación Alexander von Humboldt, Quito, pp. 72-77.

Owen, Linda. 1996, Dictionary of prehistoric archaeology. Prähistorisches Wörtebuch. Tübingen: Mo Vince.

Rodbell Donald, "Geoffrey Seltzer, David Anderson, Mark Abbott, David Enfield y Jeremy Newman. 2008, An 15.000- Year record of el Niño- Driven alleviation in southwestern Ecuador”, en: Science, vol. 283, pp. 516-520. 

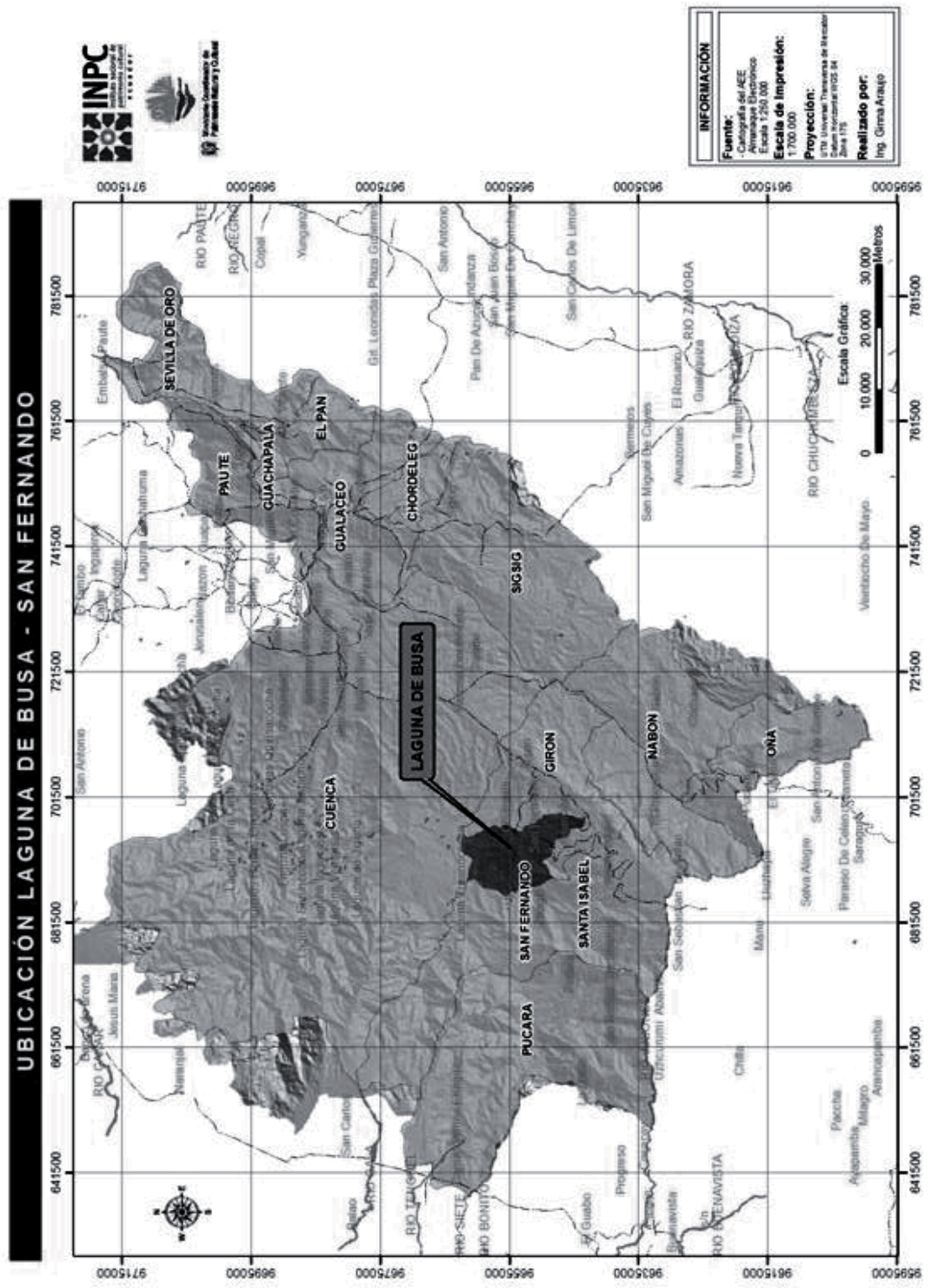

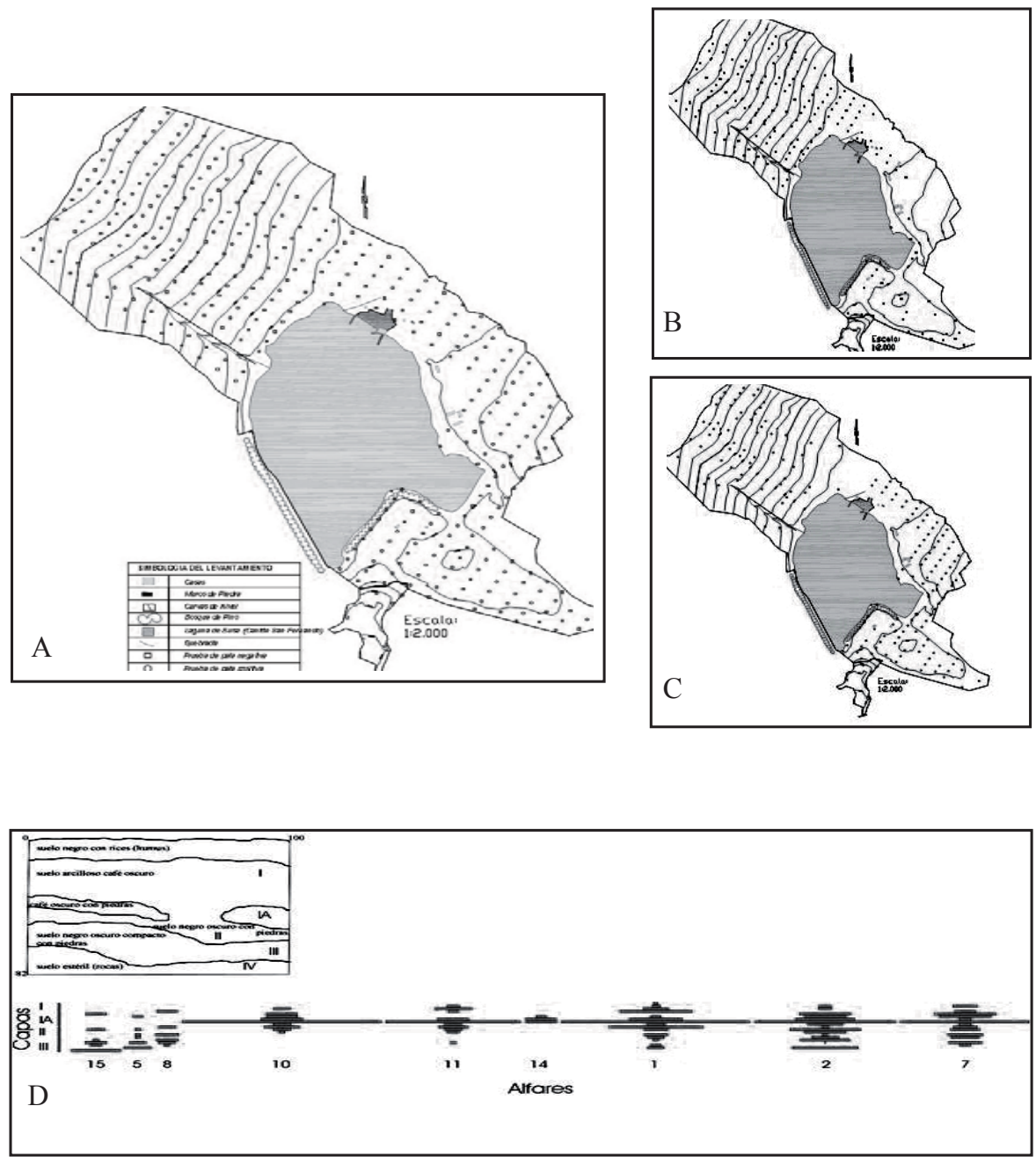

Página ANTERior:

Figura 1. Ubicación de la laguna Busa en el CATÓN SAn Fernando

\section{Arriba:}

A, FIGURA 2. ÁREA De PROSPECCIÓN

Y UBICACIÓN DE LAS PRUEBAS DE PALA; B, FIGURA 3.

Pruebas de pala positivas; C, figura 4. Pruebas

De pala Negativas; D, figura 5. Posición Relativa

De LOS tipos de alfares en el Cateo 1, Sector 1. 


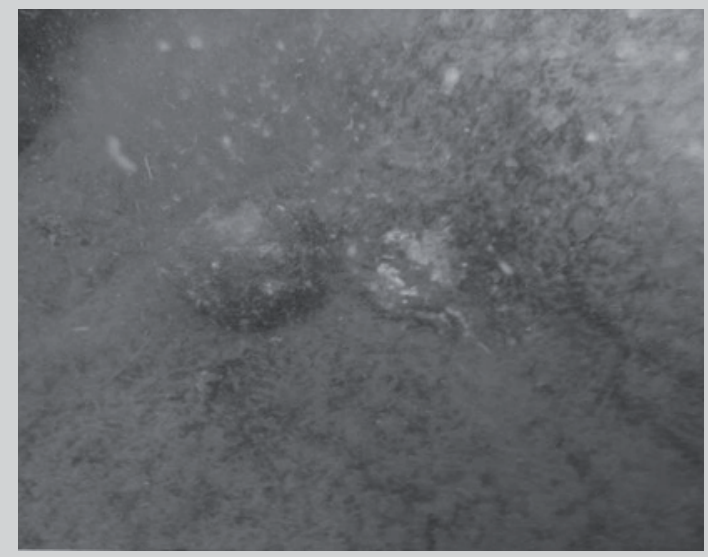

Figura 6. Hallazgo arqueológico SIN CONTEXTO EN LA LAGUNA DE BUSA.

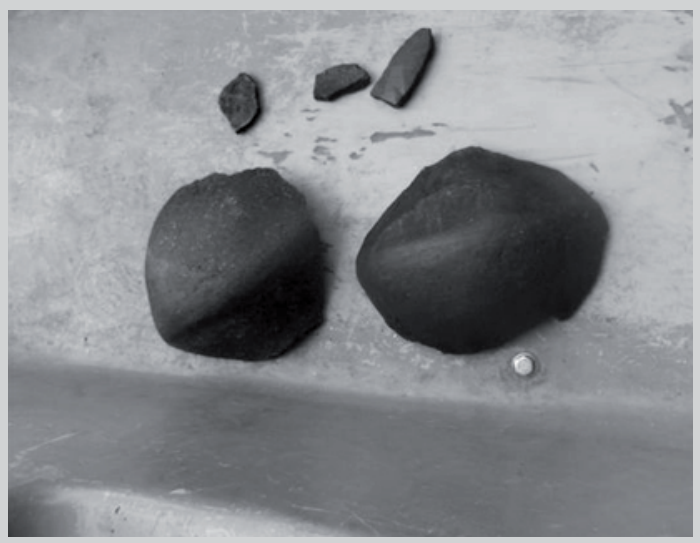

Figura 7. Vasija semicompleta fuera DE La Laguna DE BUSa. 


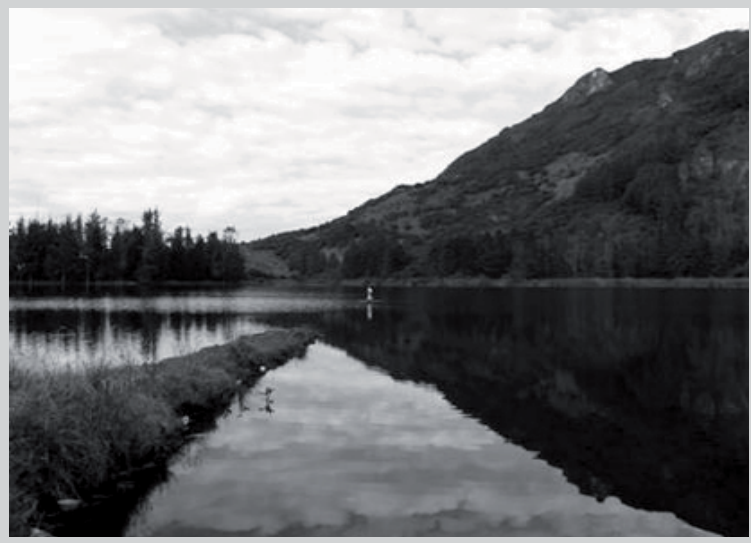

Figura 8. la laguna de Busa.

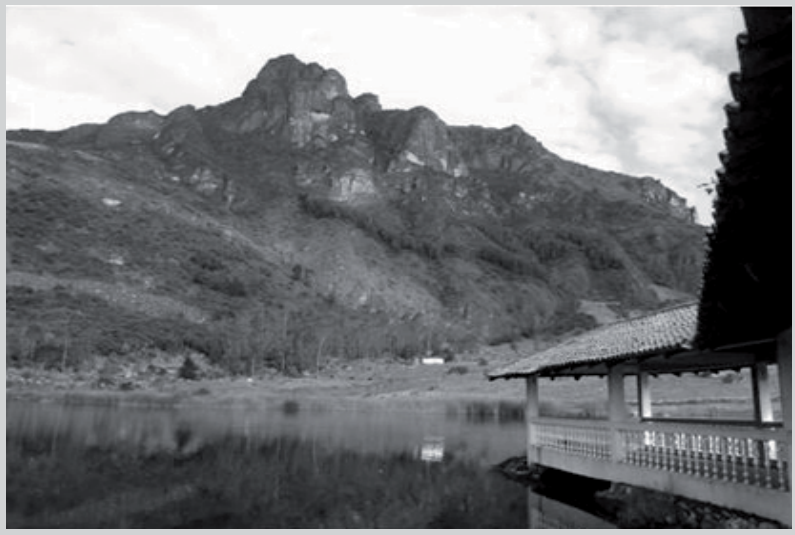

Figura 9. Vista norte del cerro San Pablo. 
